\title{
As coberturas vacinais no controle das doenças imunopreveniveis: Uma revisão
}

\section{integrativa}

\author{
Vaccination coverage in the control of immuno-preventable diseases: An integrative review \\ Cobertura vacunal en el control de enfermedades inmunoprevenibles: una revisión integradora
}

Recebido: 26/05/2021 | Revisado: 30/05/2021 | Aceito: 30/05/2021 | Publicado: 01/06/2021

\author{
Jéssyca dos Santos Gonçalves \\ ORCID: https://orcid.org/0000-0002-7005-9468 \\ Centro Universitário Santo Agostinho, Brasil \\ E-mail: jessyca.goncalves07@gmail.com \\ Dean Douglas Ferreira de Olivindo \\ ORCID: https://orcid.org/0000-0002-9433-2625 \\ Centro Universitário Santo Agostinho \\ E-mail: dean_olivindo@yahoo.com.br
}

\begin{abstract}
Resumo
O objetivo desse estudo é descrever e analisar nas publicações nacionais e internacionais a influencia das coberturas vacinais no controle das doenças imunopreveníveis no Brasil. Trata-se de uma revisão integrativa, com abordagem qualitativa. A estratégia de busca foi realizada em Maio de 2021, por acesso de forma online nas bases de dados MEDLINE (Medical Literature Analysis and Retrieval System Online), LILACS (Literatura Latino-Americana e do Caribe em Ciências da saúde), BDENF-Enfermagem (base de dados bibliográficas especializada na área de Enfermagem) e Coleciona SUS (Coleção Nacional das Fontes de Informação do Sistema Único de Saúde). Utilizaram-se os seguintes descritores: cobertura vacinal, doenças e imunização. A partir da coleta de dados, foram identificados 633 estudos. A primeira etapa da análise consistiu na aplicação dos critérios de inclusão e exclusão. Foram incluídos na pesquisa: artigos completos disponíveis de forma livre a gratuita, idiomas em português, inglês e espanhol. Excluindo-se artigos duplicados, teses e dissertações. Com isso obteve-se 31 artigo ao final da primeira etapa. Na segunda etapa, decorreu-se a leitura dos 31 estudos para detectar aqueles que respondiam a pergunta norteadora da pesquisa. Atingiu-se uma amostra de 08 estudos a serem analisados. Esse estudo demonstra que no Brasil são necessárias ações de educação em saúde que visse o conhecimento, atualização e qualificação de todos os profissionais, trabalhadores da saúde e educadores, com o objetivo de padronizar as informações sobre o calendário vacinal e as doenças imunopreveniveis, afastando assim os possíveis fatores que impedem a população há se vacinar.

Palavras-chave: Cobertura vacinal; Doenças; Imunização.
\end{abstract}

\begin{abstract}
The objective of this study is to describe and analyze the influence of vaccination coverage on the control of immunopreventable diseases in Brazil in national and international publications. This is an integrative review with a qualitative approach. The search strategy was conducted in May 2021, by online access in the databases MEDLINE (Medical Literature Analysis and Retrieval System Online), LILACS (Latin American and Caribbean Literature on Health Sciences), BDENF-Nursing (bibliographic database specialized in the Nursing area) and Coleciona SUS (National Collection of Information Sources of the Unified Health System). The following descriptors were used: vaccination coverage, diseases, and immunization. From the data collection, 633 studies were identified. The first stage of the analysis consisted of applying the inclusion and exclusion criteria. Included in the search were: full articles freely available, Portuguese, English, and Spanish languages. Duplicate articles, theses and dissertations were excluded. Thus, 31 articles were obtained at the end of the first stage. In the second stage, the 31 studies were read to detect those that answered the research's guiding question. We reached a sample of 8 studies to be analyzed. This study shows that health education actions are needed in Brazil to improve the knowledge, updating and qualification of all professionals, health workers and educators, in order to standardize the information about the vaccination schedule and immunopreventable diseases, thus ruling out possible factors that prevent people from getting vaccinated.
\end{abstract}

Keywords: Vaccination coverage; Diseases; Immunization.

\section{Resumen}

El objetivo de este estudio es describir y analizar la influencia de la cobertura de vacunación en el control de las enfermedades inmunoprevenibles en Brasil en publicaciones nacionales e internacionales. Se trata de una revisión integradora con un enfoque cualitativo. La estrategia de búsqueda se realizó en mayo de 2021, mediante el acceso en línea a las bases de datos MEDLINE (Medical Literature Analysis and Retrieval System Online), LILACS (Literatura 
Latino-Americana y del Caribe en Ciencias de la Salud), BDENF-Enfermagem (base de datos bibliográficos especializados en el área de Enfermería) y Coleciona SUS (Coleção Nacional das Fontes de Informação do Sistema Único de Saúde). Se utilizaron los siguientes descriptores: cobertura de vacunación, enfermedades e inmunización. A partir de la recopilación de datos, se identificaron 633 estudios. La primera etapa del análisis consistió en aplicar los criterios de inclusión y exclusión. Se incluyeron en la búsqueda: artículos completos de libre acceso, en idiomas portugués, inglés y español. Se excluyeron los artículos duplicados, las tesis y las disertaciones. Así, al final de la primera fase se obtuvieron 31 artículos. En la segunda etapa, se leyeron los 31 estudios para detectar aquellos que respondían a la pregunta guía de la investigación. Se llegó a una muestra de 08 estudios para ser analizados. Este estudio muestra que en Brasil son necesarias acciones de educación sanitaria que tengan como objetivo el conocimiento, la actualización y la cualificación de todos los profesionales, trabajadores de la salud y educadores, con el fin de estandarizar la información sobre el calendario de vacunación y las enfermedades inmunoprevenibles, descartando así los posibles factores que impiden que la población se vacune.

Palabras clave: Cobertura de vacunación; Enfermedades; Inmunización.

\section{Introdução}

A imunização é considerada a principal medida para o controle e prevenção de doenças, tendo como objetivo conferir ao indivíduo a imunidade, de modo que o imunobiológico administrado fornecerá a proteção. Desta forma, o conceito de vacinação é o ato de vacinar e de imunização é adquirir proteção imunobiológica contra uma doença, em geral infecciosa. A imunização pode ser classificada como ativa ou passiva (Teixeira 2019).

Implantado em 1973, o Programa Nacional de Imunizações (PNI) tem atingido altas coberturas vacinais no Brasil, de grande importância no controle de doenças transmissíveis preveníveis por imunobiológicos. Com a criação do Sistema Único de Saúde (SUS), o PNI foi reforçado. As campanhas nacionais de vacinação, voltadas para diferentes faixas etárias conforme a ocasião, proporcionaram o crescimento da conscientização social a respeito da cultura em saúde (Monteiro; Giagine; Stopa et al 2015).

Os calendários de vacinação estão regulamentados pela Portaria ministerial n 1.498, de 19 de julho de 2013, no âmbito do Programa Nacional de Imunizações (PNI), em todo o território nacional, sendo atualizados sistematicamente mediante informes e notas técnicas pela CGPNI. Nas unidades de saúde, os calendários e os esquemas vacinais para cada grupo-alvo devem estar disponíveis para consulta e afixados em local visível.

As doenças imunopreveníveis são aquelas que podem ser facilmente evitadas eficazmente através das vacinas que o Ministério da saúde disponibiliza gratuitamente na atenção primária, são elas: Catapora (varicela), Caxumba, Coqueluche (pertussis), Difteria, Doença meningocócica (DM), Doença pneumocócica (DP), Febre amarela, Gripe (influenza), Hepatite A, Hepatite B, Herpes zoster (HPV), Poliomielite, Raiva, Rotavírus, Rubéola, Sarampo, Tétano e Tuberculose (TB) (Brasil 2020).

Desde a década de 90, o comportamento das coberturas vacinais no Brasil é positivo, refletido pela aceitação da população à vacinação e pelo êxito do PNI. No entanto, é inegável o fortalecimento do movimento antivacina, o qual contribui para a queda das coberturas vacinais e favorece a reintrodução de doenças imunopreveníveis já em eliminação. Mesmo ainda tímido no Brasil, esse movimento diminui a importância da imunização, fazendo com que se propaguem informações negativas (principalmente nas redes sociais) a respeito dessa temática e com que a população hesite em vacinar as crianças. Com o atual cenário de ressurgimento de doenças imunopreveníveis, o movimento antivacina e o abandono dos esquemas multidoses pela população induzem a comportamentos e atitudes que potencializam o risco de transmissão dessas doenças, tanto no âmbito individual quanto nas redes sociais e comunitárias desse indivíduo (Silva; Araujo; Santos et al 2019).

No Brasil, a vacinação é um direito do cidadão. O Programa Nacional de Imunizações (PNI), responsável por organizar e coordenar todas as ações de vacinação, busca garantir vacinação para todos os indivíduos, independentemente da classe social e localidade de residência, área rural ou urbana.O PNI tem como missão o controle, a erradicação e a eliminação das doenças imunopreveníveis e, para tanto, o Ministério da Saúde estabelece alguns indicadores que subsidiam a análise do programa: cobertura vacinal; taxa de abandono; e taxa de homogeneidade (Fonseca; Buenafuente, 2021). 
Para Fonseca et al (2018), a vacina é um mecanismo de proteção e evita cerca de dois a três milhões de mortes anuais. Entretanto, mesmo diante de tantos dados positivos que reforçam a sua eficácia e, principalmente, sua necessidade para se atingir segurança em saúde coletiva, a recusa vacinal existe e decorre da insegurança do paciente sobre seus efeitos adversos, de não ser uma prioridade na vida de algumas pessoas ou da falta de indicação ou de prescrição por médicos que acompanham determinados pacientes.

A vacinação é uma estratégia fundamental para garantir a saúde das populações e responder à ameaça de infecções. É uma das intervenções de saúde pública mais bem-sucedidas e econômicas, prevenindo mortes em todas as faixas etárias. Com seus próprios programas e recursos, os países das Américas lideram mundialmente na eliminação de doenças evitáveis por vacinas em crianças. $\mathrm{O}$ paradigma da vacinação para crianças agora é estendido para a vacinação para todos. $\mathrm{O}$ fardo das doenças evitáveis em adultos é alto e crescente. Pacientes com doenças crônicas ou sistema imunológico enfraquecido têm maior risco de desenvolver infecções e complicações, como doença prolongada, hospitalização e até morte (Sartori et al, 2017).

A equipe de enfermagem atuante nas salas de vacina encontra-se em posição privilegiada para auxiliar na sensibilização de pais e responsáveis acerca da importância da imunização infantil. Por terem um maior contato com as mães durante a vacinação, a equipe pode transmitir informações referentes a prevenção de doenças e imunização, amainar seus medos, dúvidas e barreiras, contribuindo para que elas percebam o valor da vacinação (Morais; Quintilio, 2021).

O presente estudo tem o propósito de descrever e analisar nas publicações nacionais e internacionais a influencia das coberturas vacinais no controle das doenças imunopreveníveis e assim identificar os possíveis motivos para o retorno das doenças imunopreveniveis já erradicadas no Brasil.

\section{Metodologia}

Segundo Souza el al, (2010) o presente estudo é uma revisão integrativa $\mathrm{cm}$ caráter qualitativo, um método que proporciona a síntese de conhecimento e a incorporação da aplicabilidade de resultados de estudos significativos na prática. Foi efetuada uma busca criteriosa dos estudos escolhidos nessa revisão, a seleção, analise e discussão foram feitas de forma coerente, sem plágios e conservando a idéia original dos autores. Para a construção dessa revisão integrativa foram seguidas as sequentes etapas: Identificação do tema e seleção da pesquisa, coleta de dados após definição dos critérios de inclusão e exclusão, caracterização dos estudos, analise e interpretação dos resultados, disposição dos dados em categorias e apresentação.

Partindo do estabelecimento do problema, a questão norteadora de revisão de literatura foi: Como a cobertura vacinal influencia no controle das doenças imunopreveniveis?

A tática de busca foi realizada em Maio de 2021, por ingresso de forma online nas bases de dados MEDLINE (Medical Literature Analysis and Retrieval System Online), LILACS (Literatura Latino-Americana e do Caribe em Ciências da saúde), BDENF-Enfermagem (base de dados bibliográficas especializada na área de Enfermagem) e Coleciona SUS (Coleção Nacional das Fontes de Informação do Sistema Único de Saúde). Usaram-se os seguintes descritores em saúde: cobertura vacinal, doenças e imunização.

Com objetivo de obter uma busca ampla de estudos, os descritores controlados foram combinados de diversas maneiras, foi utilizado o DeCs (Descritores em Ciências da Saúde) combinados com as palavras-chaves, usando o boleano AND, para a elaboração de estratégias de busca no portal regional da BVS (Biblioteca Virtual em Saúde) As estratégias estão descritas abaixo (Quadro 1). 
Research, Society and Development, v. 10, n. 6, e59110616536, 2021

(CC BY 4.0) | ISSN 2525-3409 | DOI: http://dx.doi.org/10.33448/rsd-v10i6.16536

Quadro 1 - Estratégia de busca.

\begin{tabular}{|c|c|}
\hline MEDLINE & 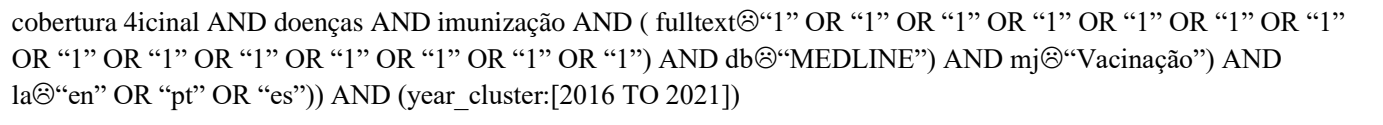 \\
\hline LILACS & 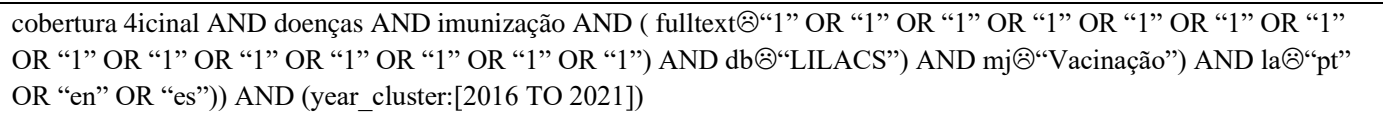 \\
\hline BDENF & 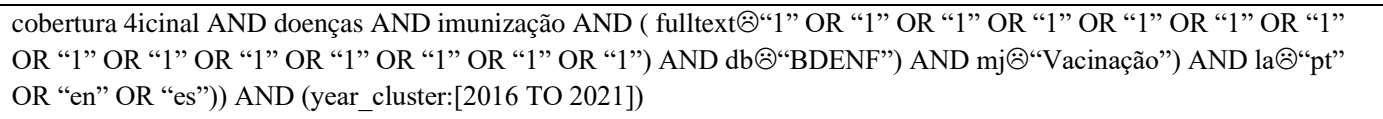 \\
\hline COLECIONA SUS & 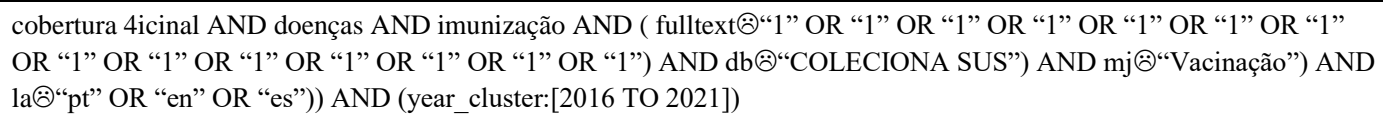 \\
\hline
\end{tabular}

Fonte: Dados da pesquisa (2021).

A partir da coleta de dados, foram encontrados 633 estudos. A primeira fase da análise consistiu na aplicação dos critérios de inclusão e exclusão. Foram incluídos na pesquisa: artigos completos disponíveis de forma livre a gratuita, idiomas em português, inglês e espanhol. Foram incluídos. Excluindo-se artigos duplicados, teses e dissertações. Com isso conseguiuse 31 artigo ao final da primeira fase. Na segunda fase, decorreu-se a leitura dos 31 estudos para encontrar aqueles que respondiam corretamente a pergunta norteadora da pesquisa e/ou tinham adequação com o fenômeno do estudo. A Figura 1 ilustra o fluxograma das etapas. 
Figura 1 - Fluxograma da coleta, análise e seleção dos artigos. Teresina - PI, brasil,2021.

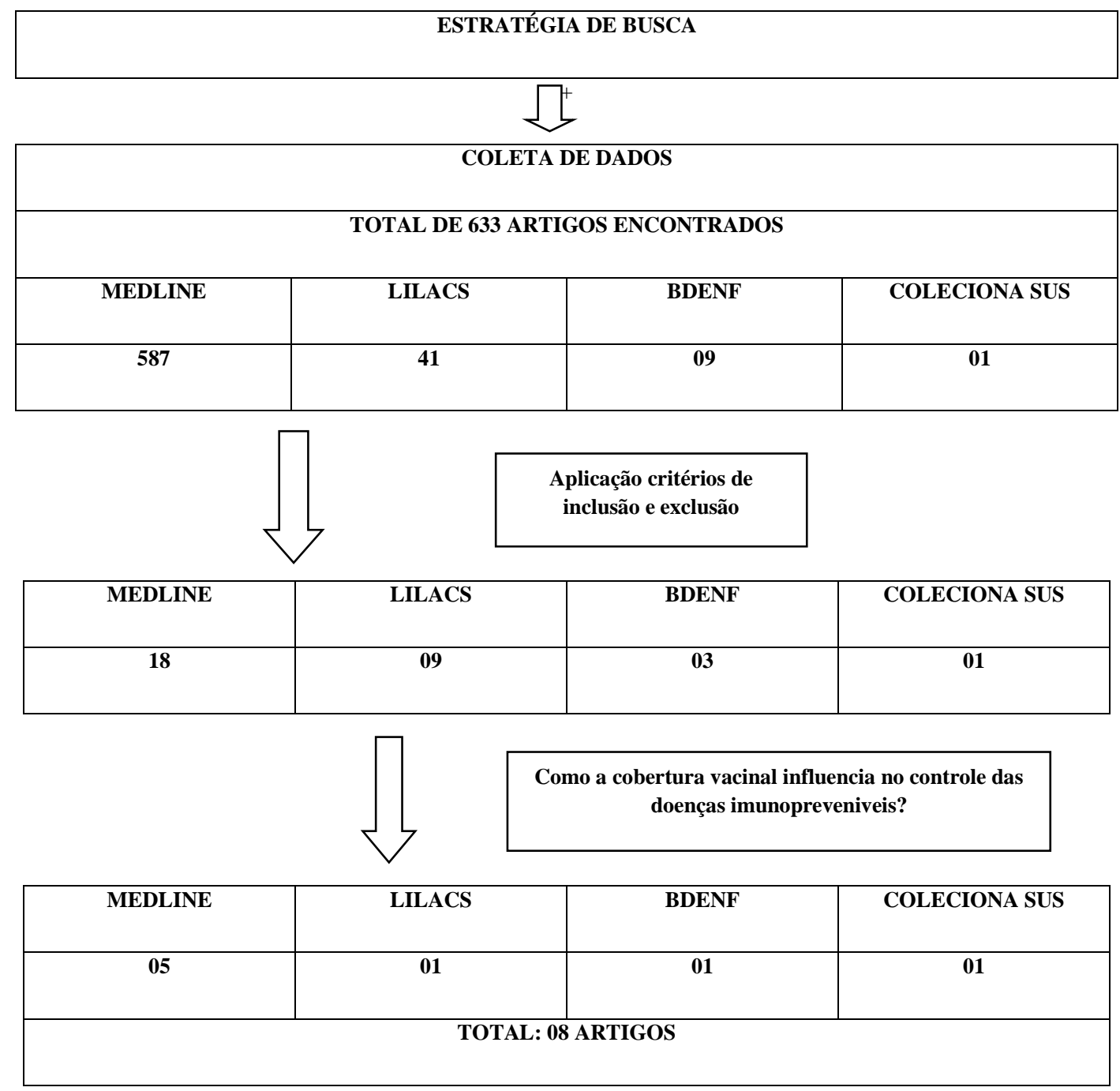

Fonte: Dados da pesquisa (2021).

O fluxograma evidencia as etapas da coleta, nálise e seleção dos artigos, resultando em uma amostra de 08 estudos inclusos na pesquisa, sendo 5 da MEDLINE, 01 da LILACS, 1 da BDENF e 01 da COLECIONA SUS. A análise e a interpretação dos dados foram organizados por meio da visualização dos dados em um quadro, apresentado nos resultados da pesquisa (Quadro 2), estruturado nas seguintes colunas: títulos do estudo/autor, abordagem, ano de publicação e objetivos.

Para compressão dos dados, após analise criteriosa dos resultados encontrados nos artigos, surgiram as seguintes temáticas a serem abordadas: Retorno de doenças imunopreveniveis; Fatores que contribuem para a queda das coberturas vacinais e Ações e estratégias para o alcance das coberturas vacinais.

\section{Resultados}

Foi observada a prevalência dos estudos no ano de 2019 com 04 artigos (50\%), um (12,5\%) em 2016, um (12,5\%) em 2017, um (12,5\%) em 2020 e um (12,5\%) em 2021.

As características dos 08 estudos inclusos nesta revisão podem ser observados no Quadro 2. Para melhor assimilação dos dados, após ampla leitura dos textos completos e análise criteriosa dos resultados encontrados nos artigos, emergiram as seguintes categorias temáticas a serem abordadas: Retorno de doenças imunopreveniveis; Fatores que contribuem para a queda das coberturas vacinais e Ações e estratégias para o alcance das coberturas vacinais (Quadro 3). 
Research, Society and Development, v. 10, n. 6, e59110616536, 2021

(CC BY 4.0) | ISSN 2525-3409 | DOI: http://dx.doi.org/10.33448/rsd-v10i6.16536

Quadro 2 - Características dos estudos segundo titulo, autor, abordagem, ano e objetivo.

\begin{tabular}{|c|c|c|c|c|}
\hline $\mathrm{N}^{\circ}$ & TITULO/AUTOR & ABORDAGEM & ANO & OBJETIVO \\
\hline 01 & $\begin{array}{l}\text { Cobertura vacinal da Pentavalente } \\
\text { e da Estratégia de Saúde da } \\
\text { Família } \\
\text { (Vieira et al, 2021) }\end{array}$ & $\begin{array}{l}\text { Qualitativa e } \\
\text { Quantitativa }\end{array}$ & 2021 & $\begin{array}{c}\text { Avaliar a cobertura vacinal da Pentavalente em } \\
\text { menores de um ano nas regiões e capitais } \\
\text { brasileiras e a cobertura da Estratégia de Saúde da } \\
\text { Família (ESF). }\end{array}$ \\
\hline 02 & $\begin{array}{l}\text { Os desafios do profissional de } \\
\text { enfermagem para uma cobertura } \\
\text { vacinal eficaz } \\
\text { (Teixeira et al, } 2019\end{array}$ & Qualitativa descritiva & 2019 & $\begin{array}{c}\text { Objetiva-se descrever os desafios encontrados } \\
\text { pelos profissionais de enfermagem para uma } \\
\text { cobertura vacinal eficaz. }\end{array}$ \\
\hline 03 & $\begin{array}{l}\text { Acesso á sala de vacinas da } \\
\text { estratégia de saúde da família: } \\
\text { Aspectos organizacionais. } \\
\text { (Ferreira et al, 2017) }\end{array}$ & Qualitativa & 2017 & $\begin{array}{c}\text { Analisar o acesso organizacional às salas de } \\
\text { vacinas nas unidades da Estratégia Saúde da } \\
\text { Família/ESF. }\end{array}$ \\
\hline 04 & $\begin{array}{l}\text { A vacinação e o saber do } \\
\text { adolescente: educação e saúde e } \\
\text { ações para a imunoprevenção. } \\
\text { (VIEGAS et al, 2019) }\end{array}$ & $\begin{array}{l}\text { Qualitativa e } \\
\text { quantitativa }\end{array}$ & 2019 & $\begin{array}{c}\text { Analisar a situação vacinal de adolescentes do } 9^{\circ} \\
\text { ano do ensino fundamental e o conhecimento } \\
\text { sobre doenças transmissíveis e as } \\
\text { imunopreveníveis }\end{array}$ \\
\hline 05 & $\begin{array}{l}\text { Áreas com queda da cobertura } \\
\text { vacinal para BCG, poliomielite e } \\
\text { tríplice viral no Brasil (2006- } \\
\text { 2016): mapas de heterogeneidade } \\
\text { regional } \\
\text { (Arroyo et al, 2020) }\end{array}$ & Estudo ecológico & 2020 & $\begin{array}{l}\text { Evidenciar áreas com queda da cobertura vacinal } \\
\text { de BCG, poliomielite e tríplice viral no Brasil }\end{array}$ \\
\hline 06 & $\begin{array}{l}\text { Indicadores de cobertura vacinal } \\
\text { para classificação de risco de } \\
\text { doenças imunopreveníveis } \\
\text { (Silva et al, 2019) }\end{array}$ & $\begin{array}{l}\text { Estudo ecológico } \\
\text { descritivo }\end{array}$ & 2019 & $\begin{array}{c}\text { Descrever os indicadores de cobertura vacinal e o } \\
\text { risco de transmissão de doenças } \\
\text { imunopreveníveis. }\end{array}$ \\
\hline 07 & $\begin{array}{l}\text { Preciso mesmo tomar vacina? } \\
\text { Informação e conhecimento de } \\
\text { adolescentes sobre as vacinas } \\
\text { (Viegas et al, 2019) }\end{array}$ & $\begin{array}{l}\text { Estudo epidemiológico } \\
\text { transversal e descritivo }\end{array}$ & 2019 & $\begin{array}{l}\text { Descrever o conhecimento dos adolescentes do } \\
9^{\circ} \text { ano do ensino fundamental de escolas públicas } \\
\text { sobre vacinas, as doenças imunopre-veníveis e as } \\
\text { doenças transmissíveis. }\end{array}$ \\
\hline 08 & $\begin{array}{l}\text { Situação da cobertura vacinal de } \\
\text { imunobiológicos no período de } \\
\text { 2009-2014 } \\
\text { (Nora et al, 2016) }\end{array}$ & Estudo de série histórica & 2016 & $\begin{array}{l}\text { Verificar a situação das coberturas vacinais nas } \\
\text { três esferas políticoadministrativas no período de } \\
\text { 2009-2014 }\end{array}$ \\
\hline
\end{tabular}

Fonte: Dados da pesquisa (2021).

Dos 08 artigos selecionados, o Quadro 2 mostra que todos os títulos e objetivos estão em concordância com os objetivos propostos na revisão, que busca identificar e analisar nas publicações nacionais e internacionais a influencia das coberturas vacinais no controle das doenças imunopreveníveis. Observou-se a prevalência de pesquisas quantitativas e qualitativas, seguidos ecológicos. 
Quadro 3 - Categorias Temáticas e frequência dos resultados nos artigos.

\begin{tabular}{|c|c|c|c|}
\hline Categoria temática & Resultados & $\begin{array}{c}\text { Artigos } \\
\text { referentes }\end{array}$ & Frequência \\
\hline $\begin{array}{l}\text { Retorno de doenças } \\
\text { imunopreveniveis }\end{array}$ & Sarampo e hepatite B & $01,04,05,06,07,08$ & $\begin{array}{c}\text { Abordado em } 06 \text { artigos } \\
80 \%\end{array}$ \\
\hline $\begin{array}{l}\text { Fatores que contribuem para a } \\
\text { baixa das coberturas vacinais }\end{array}$ & $\begin{array}{l}\text { Horário de funcionamento não adequado com } \\
\text { os horários dos trabalhadores, a falta de } \\
\text { algumas vacinas, medo da dor ou desconforto } \\
\text { na aplicação, baixa escolaridade materna, } \\
\text { gravidez na adolescência e não planejada, a } \\
\text { falta de conhecimento referente às vacinas e } \\
\text { sobre as doenças que são transmissíveis e } \\
\text { imunopreveníveis. }\end{array}$ & $\begin{array}{l}\text { Abordado em } 08 \\
\text { artigos }\end{array}$ & $\begin{array}{c}\text { Abordado em } 08 \text { artigos } \\
100 \%\end{array}$ \\
\hline $\begin{array}{l}\text { Ações e estratégias para o } \\
\text { alcance das coberturas vacinais }\end{array}$ & $\begin{array}{l}\text { Ações de intervenção por parte dos } \\
\text { profissionais de saúde estabelecer planos de } \\
\text { ações quanto as principais medidas de } \\
\text { prevenção realizadas com comunicação eficaz e } \\
\text { disponibilização de materiais educativos } \\
\text { acessíveis a toda a população }\end{array}$ & $\begin{array}{l}\text { Abordado em } 08 \\
\text { artigos }\end{array}$ & $\begin{array}{c}\text { Abordado em } 08 \text { artigos } \\
100 \%\end{array}$ \\
\hline
\end{tabular}

Fonte: Dados da pesquisa (2021).

No Quadro 3, no que consiste as categorias temáticas, em Retorno de doenças imunopreveniveis, foi associadas as doenças que estavam em baixa ou foram erradicas no Brasil. Assim como Fatores que contribuem para a baixa das coberturas vacinais, mostra os motivos pelos quais a população não esta se vacinando. Em relação as Ações e estratégias para o alcance das coberturas vacinais, mostra orientações do que pode ser realizado pra obter o retorno da população a vacinação.

\section{Discussão}

Os resultados obtidos nesse estudo mostra que as coberturas vacinais são mais que importantes no controle das doenças imunopreveniveis e que são inversamente proporcionais, quando as coberturas estão em alta as doenças permanecem em baixa ou erradicadas, e quando ocorre a baixa das coberturas vacinais doenças imunopreveniveis retornam ao nosso cotidiano.

Na década de 1990, foram publicados artigos sobre a possível associação entre a vacina SCR e a doença de Crohn e mais tarde, a ligação dessa vacina com autismo. Mesmo após outros trabalhos refutarem essa relação, esse sentimento ainda perdura na população e tais informações ainda são difundidas, atualmente, de forma mais ágil por meio da internet. As consequências são as frequentes epidemias de doenças imunopreveníveis, como sarampo e coqueluche que ocorrem atualmente em todo o mundo, e a ameaça da reintrodução da poliomielite em regiões nas quais já foi eliminada (Sato, 2018).

Para Silva et al (2020), nas últimas décadas houve grande avanço no que tange à redução da mortalidade infantil, sobretudo em relação às doenças transmissíveis. Tal fato tornou-se possível através da ampliação do acesso aos serviços de saúde e da criação de estratégias e intervenções de saúde direcionadas à população infantil. Uma das principais estratégias adotadas pelo Brasil para diminuir a mortalidade infantil por doenças imunopreveníveis foi a introdução rotineira de ações de vacinação. 
Conforme Teixeira et all, (2019) a cobertura vacinal é uma estratégia de saúde que demanda dos profissionais enfermeiros uma assistência qualificada, capaz de controlar doenças imunopreveníveis, evitando, assim, as doenças e a redução da morbimortalidade da população.

Desde janeiro de 2018, foram verificados surtos de sarampo nos estados de Roraima e Amazonas, contabilizando, até o mês de junho de 2018, 314 casos O surto de sarampo ocorrido no Brasil evidencia as consequências da redução do número de vacinados, que vem ocorrendo anualmente no país. A taxa de cobertura da tríplice viral, que alcançava $96 \%$ das crianças em 2015, baixou para 84\% em 2017 e possibilitou o retorno da infecção no país (Arroyo 2020).

Para Viegas et all, (2019) é preocupante a baixa cobertura vacinal contra hepatite B entre os adolescentes, principalmente na faixa etária de 15 a 18 anos. Se considerarmos que a vacina da hepatite $\mathrm{B}$ foi introduzida no calendário básico do PNI em 1997 para todos os menores de 1 ano, e ampliada para as faixas etárias de 1 a 19 anos em 2001, podemos inferir que oportunidades perdidas de vacinação continuam ocorrendo. Profissionais de saúde precisam estar atentos ao cartão vacinal dos jovens e, em cada oportunidade, tirar proveito de sistemas de informação de imunização e oferecer todas as vacinas elegíveis para os adolescentes.

Um estudo realizado no estado do Ceará por Silva et all, (2019) evidenciou que alguns de seus municípios, no ano de 2015, também apresentaram baixa cobertura para a tríplice viral (sarampo, rubéola e caxumba) e apresentaram casos confirmados de sarampo. Há algumas justificativas para o surgimento desses surtos, as quais se referem, justamente, à importação de casos, à alta transmissibilidade dessas doenças e à falta de homogeneidade das coberturas vacinais, fazendo com que uma parcela da população fique suscetível.

De acordo com Viegas et all, (2019) coberturas vacinais baixas ou mesmo próximas às metas estabelecidas são insuficientes para erradicar ou controlar doenças imunopreveníveis, predispondo episódios de surtos. Segundo a OMS (2019), desde 2013 o país vem registrando queda das coberturas vacinais. Doenças consideradas erradicadas, como a poliomielite, são ameaças à população devido ao descaso com a medida de prevenção. Atualmente, o cenário de surto ativo de sarampo, considerada erradicada, e as baixas coberturas vacinais para todas as regiões, demonstram a enorme influencia dos grupos de recusa ao país.

Uma pesquisa epidemiológica realizada no Brasil no período de 2001 a 2016 constatou que 662 crianças menores de um ano adoeceram por difteria, tétano e coqueluche. Em concordância com o calendário nacional de vacinação, essas doenças podem ser prevenidas através da vacina pentavalente, que previne também hepatite B e infecções cruzadas pelo Haemophilus influenzae B, devendo ser aplicada a primeira dose ao segundo mês de vida do bebê, a segunda dose ao quarto mês e a terceira dose ao sexto mês (Souza, 2018).

As coberturas vacinais em algumas regiões brasileiras onde não ocorre de forma homogênea, e estão abaixo de 95\%, a doença tende a se comportar de forma endêmica, e com ocorrência de epidemias a cada 2 a 3 anos. Em contrapartida, outros países que conseguem manter níveis altos da cobertura vacinal, a incidência é reduzida, ocorrendo em períodos que variam de 5 a 7 anos10 (Machado et al, 2020).

Para Nora et all, (2016) indubitavelmente, inquéritos de coberturas vacinais devem ser realizados frequentemente para que se possa planejar ações de busca-ativa, prevenindo o reaparecimento de doenças até então erradicadas.

\section{Conclusão}

A partir da analise dos artigos estudados entende-se que a influencia das coberturas vacinais é proporcional ao controle das doenças imunopreveniveis, a medida que as coberturas vacinais estão em alta, as doenças imunopreveniveis se encontram em controle ou em baixa. Esse estudo demonstra que no Brasil são necessárias ações de educação em saúde que visse o conhecimento, atualização e qualificação de todos os profissionais, trabalhadores da saúde e educadores, com o 
propósito de padronizar as informações sobre o calendário vacinal e as doenças imunopreveniveis, afastando assim os possíveis fatores que impedem a população há se vacinar.

A autora ainda sugere uma aliança com o setor privado, elaborando projetos de educação em saúde em locais freqüentemente visitados pela população, assim prevenindo e ofertando mais saúde e qualidade de vida para todos.

Esse estudo servirá como embasamento para o desenvolvimento de futuros trabalhos científicos sobre essa temática, visto que aumentando assim as pesquisas sobre a relevância das coberturas vacinais no controle das doenças imunopreveniveis, surgiram novas estratégias em busca da imunização, novas formas de monitoramento, registro das vacinas e levantamento de dados sobre as doenças imunopreveniveis e seu retorno no território brasileiro.

\section{Referências}

Arroyo, L. H., et al. (2020). Áreas com queda da cobertura vacinal para BCG, poliomielite e tríplice viral no Brasil (2006-2016): mapas da heterogeneidade regional. Cad. Saúde Pública, 36(4): 00015619.

Brasil (2020).

Ferreira, A. V., et al. (2017). Acesso á sala de vacinas da estratégia saúde da família: aspectos organizacionais. Revista de enfermagem UFPE, 11(10): 386977.

Fonseca, M. S. et al. (2018). Recusa da vacinação em área urbana do norte de Portugal. Scientia Medica, $28(4): 2$.

Fonseca, K. R., Buenafuente, S. M. F (2021). Análise das coberturas vacinais de crianças menores de um ano em Roraima, 2013-2017. Epidemiol. Serv. Saúde, 30 (2).

Machado, L. F. B. et al. (2020). Recusa vacinal e o impacto no ressurgimento de doenças erradicadas. Braz. J. Surg. Clin. Res. 32(1): 12-16.

Morais, J. N., Quintilioa, M. S. V. (2021). Fatores que levaram à baixa cobertura vacinal de crianças e o papel da enfermagem - Revisão Literária. Revista interfaces, 9(2): 1054-1063.

Monteiro, C. N., et al. (2018). Cobertura vacinal e utilização do SUS para vacinação contra gripe e pneumonia em adultos e idosos com diabetes autorreferida, no município de São Paulo. Epidemiologia e Serviços de Saúde, 27(2).

Nora T. T. D. et al. (2016). Situação da Cobertura vacinal de imunológicos no período de 2009-2014. Revista Enfermagem UFSM, 6(4): 482-493.

Organização Mundial de Saúde. (2019). Dados de Vigilância de Sarampo

Sartori G. P., Brasó, P. \& e Medina, J. (2017). Conhecimento de médicos especialistas ou em treinamento sobre vacinas não sistemáticas no Uruguai. Medical Journal of Uruguay, 33(1): 72-99.

Silva, I. et al (2020). Situação vacinal de Meningocócica C e Peneumocócica 10 valente em crianças matriculadas na educação infantil. Revista Saúde e Pesquisa, 13 (1): 105-113.

Silva, A. B. S., et al. (2019). Indicadores de cobertura vacinal para classificação de risco de doenças imunopreveníveis. Rev Bras Promoç Saúde, $32: 9285$.

Sato, A. P. (2018). Qual a importância da hesitação vacinal na queda das coberturas vacinais no Brasil? Revista de Saúde Pública. 52.

Souza, M. T., Silva, M. D. \& Carvalho, R. (2010). Revisão integrativa: O que é e como fazer? Revista Einstein, 8(1).

Souza, B. S. Q. (2018). Epidemiologia dos casos de óbitos pelas doenças imunopreviníveis: Difteria, Tétano e Coqueluche em crianças menores de um ano no brasil entre 2001 a 2016. Trabalho de Conclusão de Curso (Graduação) Centro universitário de Brasília (UniCEUB) 45.

Teixeira, V. B., et al. (2019). Os desafios do profissional de enfermagem para uma cobertura vacinal eficaz. Revista Nursing, 22(251): 2862-2867

Vieira, M. L., et al. (2021). Cobertura vacinal da Pentavalente e da Estratégia de Saúde da Família. Rev. Enferm. UFSM, 11(16), 1-21.

Viegas S. M. F., et al. (2019). Preciso mesmo tomar vacina? Informação e conhecimento de adolescentes sobre as vacinas. Av Enferm, $37(2), 217-226$.

Viegas, S. M. F., et al. (2019). A vacinação e o saber do adolescente: educação em saúde e ações para a imunoprevenção. Ciênc. saúde coletiva, 24(2): 351360 .

Zambonin, F., et al. (2019). Análise da cobertura vacinal em menores de cinco anos em um estado fronteiriço da Amazônia. Saúde em Redes, 5(2):289299. 